\title{
Desafios do uso do livro didático no ensino
} superior: uma análise empírica exploratória da
recepção de aspectos de vocabulário, gramática
e exercícios do livro DaF Kompakt

[Challenges in textbook use at the university level - an exploratory empirical analysis of acceptance of aspects related to vocabulary, grammar and exercises in the DaF Kompakt textbook]

http://dx.doi.org/10.11606/1982-88372237302

\author{
Anelise Gondar ${ }^{1}$ \\ Mergenfel A. $\bigvee_{\text {az Ferreira }}{ }^{2}$
}

\begin{abstract}
Among the many available foreign language (FL) resources, textbooks have undoubtedly been one of the core elements in teaching-learning mechanisms in classrooms for many decades (RöSLER; SCHART 2016). This paper extends current discussions on the use of textbooks for teaching German as a Foreign Language, specifically within the context of Brazilian universities. The purpose here is to present and provide a critical discussion - based on an exploratory-interpretive survey (CASPARI; HELBIG; SCHMELTER 2007) - of student perceptions of the textbook DaF Kompakt, used by one university in Rio de Janeiro, Brazil, that offers Portuguese and German Language and Literature Studies. This paper opens with an initial discussion of the role of the textbook and student beliefs and perceptions about teaching and learning German as a Foreign Language; it then presents and analyses the data collected through a qualitative survey of university students; finally, it suggests a research agenda exploring possibilities of critical analyses of foreign language textbook use, together with a comparative investigation in greater depth, exploring the limits and possibilities of the materials used in German language courses at universities in Brazil.
\end{abstract}

Keywords: Textbook Analysis; German as a Foreign Language; Qualitative Survey

Resumo: Dos vários recursos disponíveis ao aprendizado da língua estrangeira (LE), o livro didático tem provado ser indubitavelmente um dos elementos centrais para os mecanismos de ensino-aprendizagem em nossas salas de aula ao longo das décadas (RÖSLER; SCHART 2016). Este artigo avança as discussões atuais acerca da utilização do livro didático de alemão como língua estrangeira (ALE) especificamente no contexto do ensino superior brasileiro e tem como objetivo apresentar e discutir criticamente a partir de uma pesquisa exploratório-interpretativa (CASPARI; Helbig; SCHMELTER 2007) a percepção dos alunos sobre o livro didático DaF Kompakt, utilizado por uma universidade pública no Rio de Janeiro que oferece o Curso de Letras Português-Alemão. O artigo apresenta inicialmente uma discussão acerca do papel do livro

\footnotetext{
${ }^{1}$ Universidade do Estado do Rio de Janeiro, R. São Francisco Xavier, 524, Rio de Janeiro, RJ, 20550900, Brasil. E-mail: anelisegondar@gmail.com. ORCID: 0000-0001-7594-8857

${ }^{2}$ Universidade Federal do Rio de Janeiro, Av. Horácio de Macedo, 2151, Rio de Janeiro, RJ, 22280002, Brasil. E-mail: megchenvaz@yahoo.com. ORCID: 0000-0002-6478-8066
}

\section{(cc) BY-NC}

Pandaemonium, São Paulo, v. 22, n. 37, mai.-ago. 2019, p. 302-330 
GONDAR, A; FERREIRA, M. - Desafios do uso do livro didático no ensino superior

didático e das crenças e percepções discentes sobre ensino-aprendizagem de ALE, em seguida apresenta e analisa os dados coletados por meio de pesquisa qualitativa junto a discentes do ensino superior e, por fim, propõe uma agenda de pesquisa que aponta para possibilidades de análise crítica do uso do livro didático de língua estrangeira e de uma investigação mais aprofundada e contrastiva sobre limites e possibilidades dos materiais usados em cursos de língua alemã nas universidades brasileiras.

Palavras-chave: análise de livro didático; alemão como língua estrangeira; pesquisa qualitativa.

Zusammenfassung: Von den vielen Ressourcen, die dem Fremdsprachenstudium zur Verfügung stehen, hat sich das Lehrwerk zweifellos über die Jahrzehnte als eines der zentralen Elemente für Lehr-Lern-Prozesse in unseren Klassenräumen erwiesen (RÖSLER; SCHART 2016). Dieser Artikel leistet einen wichtigen Beitrag zu der aktuellen Diskussion über die Verwendung des Lehrwerks DaF Kompakt im speziellen Kontext der brasilianischen Hochschulbildung und zielt darauf ab, die Wahrnehmung von Studierenden im Rahmen des Studiengangs ,Sprach- und Literaturwissenschaft Portugiesisch-Deutsch ' einer Universität im Bundesstaat Rio de Janeiro, die das Lehrwerk verwendet, anhand eines explorativ-interpretativen Forschungsansatzes vorzustellen und zu diskutieren (CASPARI; HELBIG; SCHMELTER 2007). Der Artikel stellt zunächst die Diskussion über die Rolle des Lehrwerks und die studentischen Überzeugungen und Wahrnehmungen über die Lehre und das Erlernen von Deutsch als Fremdsprache dar. Im Anschluss werden dann die Daten, die durch qualitative Forschung mit Hochschulstudierenden gesammelt wurden, vorgestellt und analysiert. Schließlich wird eine Forschungsagenda vorgeschlagen, die sowohl auf die Möglichkeiten für eine kritische Analyse der Verwendung des Fremdsprachenlehrwerks als auch auf die Perspektiven für eine vertiefte und kontrastive Untersuchung der Grenzen und Möglichkeiten der Lehrmaterialien, die in Deutschkursen an brasilianischen Universitäten verwendet werden, hinweist.

Stichwörter: Lehrwerkanalyse; Deutsch als Fremdsprache; qualitative Forschung

\section{Introdução}

Dos vários recursos disponíveis ao aprendizado de LEs, o livro didático tem provado ser indubitavelmente um dos elementos centrais para os mecanismos de ensinoaprendizagem em nossas salas de aula ao longo das décadas (RöSLER; SCHART 2016; MourA et al. 2017). Utilizados nas mais diversas etapas da aprendizagem escolar e extraescolar, os materiais didáticos, em especial de língua estrangeira, refletem, por um lado, as políticas linguísticas para um determinado Estado ou região, ao mesmo tempo em que têm respondido aos desafios do século XXI como, por exemplo, a incorporação de novas tecnologias e dos estímulos em um mundo em constante transformação (entre outros, ver MARQUES-SCHÄFER; ROZENFELD 2018). A pesquisa em torno de materiais didáticos em geral e livros didáticos em particular deita raízes nas reflexões acerca das formas de aprendizagem de uma língua estrangeira e se confunde com a história e análise dos próprios métodos de ensino de LEs ao longo da história da didática (RÖSLER 2012). O uso do livro didático no ensino superior brasileiro em cursos de alemão como língua 
GONDAR, A; FERREIRA, M. - Desafios do uso do livro didático no ensino superior

estrangeira (ALE), em especial, apresenta dificuldades que vêm sendo debatidas por especialistas do campo no contexto brasileiro (BOHUNOVSKY; BOLOGNINI 2005; UPHOFF 2009; SCHMIDT 2016; MARQUES-SCHÄFER; BOLACIO; STANKE; 2016).

Este artigo avança as discussões atuais acerca da utilização do livro didático para ALE no ensino superior brasileiro e tem como objetivo apresentar, a partir de uma pesquisa exploratório-interpretativa (CASPARI; HELBIG; SCHMELTER 2007), a percepção discente sobre o livro didático atualmente adotado pela Universidade do Estado do Rio de Janeiro, que oferece o Curso de Letras Português-Alemão. Nesse sentido, busca contribuir para o preenchimento de uma das lacunas já apontadas por Schmidt (2016) e Marques-Schäfer, Bolacio e Stanke (2016) na literatura, no que diz respeito a uma análise ao mesmo tempo mais ampla e, também, multifacetada do uso de livros didáticos, em especial do livro DaF Kompakt, no ensino superior brasileiro. Em consonância com Caspari, Helbig e Schmelter (2007: 499), a pesquisa que dá origem a este artigo tem como ponto de partida a ideia de que a realidade de inserção do docente-pesquisador pode e deve contribuir para a criação e avanço de marcos teóricos no contexto da área de estudos de ALE. O que os autores denominam como um acompanhamento de pesquisa (atento) à prática de sala de aula (forschende Begleitung von unterrichtlicher Praxis) (ibidem), permite que

[...] o professor de língua estrangeira possa formular questionamentos relevantes e concretos em relação ao seu campo de atuação profissional, levantando, analisando e interpretando sistematicamente dados a fim de desenvolver sua prática de forma embasada. (CASPARI; HELBIG; SCHMELTER 2007: 499, tradução nossa) ${ }^{3}$

A partir dessa perspectiva, a presente pesquisa busca verificar na percepção dos estudantes, ecos da própria compreensão docente quanto ao trabalho com o livro didático DaF Kompakt, procurando, além disso, apreender a reflexão destes acerca de sua própria relação com o material, bem como suas expectativas quanto a esse instrumento de aprendizagem.

A ferramenta utilizada para coleta de dados mais precisos sobre a relação dos estudantes com o livro didático consistiu em um questionário distribuído eletronicamente a um total de trinta alunos regularmente frequentando todas as disciplinas de Língua Alemã (II, IV e VI) ofertadas em 2017.1 na referida instituição de ensino superior. O

\footnotetext{
${ }^{3}$ No original: "[...] Fremdsprachenlehrer für sie relevante, konkrete Fragestellungen in Bezug auf ihr berufliches Handlungsfeld formulieren, hierzu systematisch Daten erheben, diese analysieren und interpretieren und auf dieser Basis ihr Handeln begründet weiterentwickeln".
}

Pandaemonium, São Paulo, v. 22, n. 37, mai.-ago. 2019, p. 302-330 
GONDAR, A; FERREIRA, M. - Desafios do uso do livro didático no ensino superior

questionário contou com nove perguntas relativas a elementos específicos do livro didático que, segundo a experiência de ensino das docentes-pesquisadoras, indicaram ser os que mais representavam algum tipo de entrave ao processo de aprendizagem. Dessa forma, nortearam a presente pesquisa as dificuldades sentidas pelas docentespesquisadoras quanto ao (1) vocabulário (a quantidade, forma de apresentação e sistematização do vocabulário novo a cada lição); (2) aos conteúdos gramaticais (quantidade, forma de apresentação e sistematização dos pontos gramaticais a cada lição); e (3) à tipologia de exercícios oferecida pelo livro. A partir do acompanhamento atento da prática pedagógica em sala de aula, foram identificadas as seguintes questões que reiteradamente evocavam comentários dos alunos: dificuldades em relação às questões de vocabulário (surgimento de vocabulário novo durante a lição e uso da lista de vocábulos ao final de cada lição), à progressão e apresentação dos conteúdos gramaticais (a quantidade de pontos gramaticais apresentados por lição e a forma como surgem no livro) e à tipologia de exercícios. Com base nessas indagações, construiu-se um instrumento de pesquisa de característica tanto quantitativa quanto qualitativa para apreender tanto as avaliações dos alunos em relação aos referidos pontos quanto as características gerais do livro didático. Ao elucidar esses três aspectos trazidos pelo livro didático, a proposta central do artigo foi a de identificar como estes são recebidos pelos aprendentes e em que medida os aspectos mencionados são fatores facilitadores ou desafiadores do ponto de vista da aprendizagem.

Tendo em vista esse objetivo principal, será apresentada uma breve discussão sobre o uso do livro didático (LD) em contexto universitário e sobre algumas crenças de aprendizes acerca de aspectos que envolvem o processo de aprendizagem, como o próprio livro didático e o modo como é (ou pode ser) utilizado. A presente investigação encontrase inspirada nos critérios elencados por Caspari, Helbig e Schmelter (2007) para a aplicação de pesquisas exploratório-interpretativas. Os autores consideram relevantes a abertura e a flexibilidade frente à combinação de instrumentos qualitativos e quantitativos de coleta e avaliação de dados, a comunicabilidade dos achados e a transparência nos critérios relativos à concepção e reflexão sobre o tema central da pesquisa e suas implicações. Seguindo estes princípios, que justificam uma pesquisa exploratória cientificamente embasada, este estudo busca apresentar, a partir do material coletado, discussões e encaminhamentos necessários do ponto de vista da análise e 
GONDAR, A; FERREIRA, M. - Desafios do uso do livro didático no ensino superior

aperfeiçoamento da prática docente em sua interface com o livro didático e o propósito do ensino de ALE em nível superior.

\title{
$2 \bigcirc$ livro didático - alguns elementos para reflexão
}

\author{
"Na maioria dos contextos de aula, o livro didático segue \\ tendo um papel fundamental. E ainda assim, a crítica ao livro didático \\ permanece inconfundível" (RÖSLER; SCHART 2016: 483)4.
}

É possível afirmar que a literatura especializada no estudo de livros e materiais didáticos acompanhou o avanço dos tipos de materiais e recursos trazidos para o contexto da sala de aula ao longo das décadas (RÖSLER 2012: 33 em diante). A evolução das características e objetivos do ensino de língua estrangeira associada às transformações na própria natureza dos materiais pedagógicos disponíveis aos aprendentes tem feito com que o livro didático passe a disputar seu lugar dentre uma miríade de inputs em diversos suportes (MourA et al. 2017). Tanto jornais quanto páginas eletrônicas, aplicativos, blogs, redes sociais e filmes instigam a interatividade, a individualização do aprendizado e, sobretudo, parecem ter potencial de descentrar o livro didático como autoridade linguística e cultural (MARQUES-SCHÄFER; ROZENFELD 2018). Nesse sentido, a própria percepção acerca do livro didático é a de que ele deveria ter como foco

[...] acompanhar ou orientar o processo de aprendizagem dentro de um determinado espaço de tempo e lidar com a variedade de fenômenos linguísticos e culturais da língua alvo, além de relacionar tudo isso a diferentes perspectivas didáticas ${ }^{5}$ (RÖSLER 2012: 41 apud RÖSLER; SCHART 2016: 484, tradução nossa).

\begin{abstract}
Afinal,
[...] um livro didático não deve apenas fornecer textos e temas, mas, sim, responder ao conjunto de exigências no que tange ao trabalho linguístico nos campos da pronúncia, do léxico, do vocabulário, da gramática, do trabalho textual etc. e unir isso a uma variedade de exercícios e $\operatorname{tarefas}^{6}$ (RÖSLER; SCHART 2016: 485, tradução nossa).
\end{abstract}

\footnotetext{
4 Tradução livre do original em alemão: "In den meisten Unterrichtskontexten spielen Lehrwerke nach wie vor eine zentrale Rolle. Und dennoch sind die kritischen Stimmen unüberhörbar".

${ }^{5}$ Do original: “[...] 'den Lernprozess für einen bestimmten Zeitraum zu begleiten oder zu steuern und die Vielfalt der sprachlichen und kulturellen Phänomene der Zielsprache zu behandeln und unter didaktischen Gesichtspunkten in Beziehung zu bringen".

${ }^{6}$ Do original: “ $[. .$.$] ein Lehrwerk soll ja nicht nur Texte zu Themen liefern, sondern die Gesamtheit der$ Anforderungen an Spracharbet in den Bereichen der Aussprache, Lexik, Wortschatz, Grammatik, Textarbeit usw. abdecken und in einer Übungs- und Aufgabenvielfalt verbinden".
}

Pandaemonium, São Paulo, v. 22, n. 37, mai.-ago. 2019, p. 302-330 
GONDAR, $A_{i}$ FERREIRA, M. - Desafios do uso do livro didático no ensino superior

Analisando historicamente os materiais didáticos disponíveis para o ensino de alemão como LE, Rösler (2012) afirma que, especificamente nos anos 60, os materiais didáticos de modo geral mantinham os aprendentes longe da variedade de produções orais do contexto cultural da língua-alvo e apresentavam-se distanciados de uma competência linguística adequada a múltiplos contextos de uso. Na década de 70, uma das grandes críticas, segundo o mesmo autor (ibidem: 38), direcionadas aos livros didáticos, era a pouca autenticidade de seus inputs linguísticos - característica que distanciava o aprendente das condições materiais e concretas de produção do discurso na língua estrangeira. A aprendizagem de uma comunicação distante da realidade local da línguaalvo fomentava a aprendizagem de uma chamada "língua do livro didático" (Lehrbuchsprache), algo, no melhor dos casos, apenas prototípico da realidade comunicativa do ambiente social da língua estrangeira. Ao longo das décadas, foi necessário repensar a função do material didático. Segundo Rösler (2012: 47), materiais e livros didáticos atuais têm em comum, em linhas gerais, a apresentação de fenômenos linguísticos e culturais a serem introduzidos conforme uma lógica de nivelamento dos conhecimentos e competências dos alunos. Também primam por uma certa variedade de gêneros textuais, buscam oferecer uma quantidade diversa e suficiente de exercícios e tarefas e, por fim, devem servir como subsídio ao estudo autônomo, fora do contexto da sala de aula.

Contudo, um dos elementos que se impõem do ponto de vista da prática reflexiva reside no questionamento sobre as formas de uso do livro didático e sua capacidade em atender às necessidades dos alunos e às demandas específicas do contexto universitário. Nesse sentido, é necessário pensar aspectos críticos tanto em relação à concepção desses livros quanto ao seu uso.

Um dos aspectos tematizados por diferentes autores da área da linguística aplicada (KumaraVAdivelu 2001; PrabHU 1990), mais voltados para o ensino do inglês como língua estrangeira, refere-se ao fato de livros didáticos estarem ligados a um método ou métodos de ensino, e apresentarem como característica essencial uma pretensa universalidade, negligenciando, muitas vezes, o contexto dos aprendentes, seus interesses e motivações. Assim, reconhecer as especificidades de um curso de Letras PortuguêsAlemão com foco na formação de docentes de língua alemã implica problematizar o uso do LD e trabalhar com a hipótese da inexistência de um livro didático disponível no mercado adequado a um contexto tão específico e que atenda às demandas de proficiência 
GONDAR, A; FERREIRA, M. - Desafios do uso do livro didático no ensino superior

linguística e cultural de uma formação desta natureza. Deve-se, portanto, constantemente problematizar e discutir o uso do livro didático como um "ritual pedagógico" (PRABHU 1990: 171) ou como um "elemento central”, em torno do qual objetivos são estabelecidos, programas de cursos são desenvolvidos, conteúdos definidos e, até mesmo, avaliações são elaboradas.

No que tange especificamente a esta pesquisa, as discussões sobre padronização, gradação e facilitação em relação aos conteúdos presentes no LD são de especial interesse. Livros didáticos reúnem mecanismos específicos de aprendizagem e podem evidenciar uma redução didática. Para Lehner (2012: 9) a redução didática caracteriza qualquer prática que vise à transmutação de dados "abrangentes e complexos" em fenômenos "evidentes e compreensíveis" aos estudantes. O modo como tal prática ocorre nos LDs, no caso do presente estudo no livro DaF Kompakt, é um dos aspectos a serem discutidos a partir da percepção dos aprendentes sobre os elementos apontados no questionário.

Por sua vez, o fenômeno da redução didática está estreitamente relacionado à questão da quantidade e qualidade dos insumos ofertados. Krashen (1985) defendeu, em tese sobre aquisição de segunda língua, o que chamou de "insumo compreensível": para o autor, o aprendizado ocorreria de forma eficaz, à medida que aprendizes fossem tendo acesso a insumos relevantes e compreensíveis de acordo com seus níveis de aprendizado. Desse modo, desenvolveu a fórmula $i+1$, em que $i$ se refere ao nível de aprendizagem em que o aluno se encontra e +1 se refere a um nível imediatamente acima. Entretanto, o próprio autor salienta que os materiais didáticos e insumos ofertados, de uma forma geral não precisam (nem devem) estar restritos à fórmula $i+1$. Para o autor, se o aprendiz for capaz de compreender uma informação adequadamente, isso significa que o $i+1$ está sendo automaticamente contemplado. Assim, para Krashen, a quantidade e adequação do insumo seriam aspectos mais importantes que a ordem da apresentação de conteúdos. Autores como McLaughlin (1987) e Callegari (2004) apontam que grande parte dos materiais e livros didáticos segue uma sequência que pode ser descrita como arbitrária, uma vez que não há estudos comprobatórios suficientes sobre uma progressão e sequência de aprendizagem/ aquisição natural de uma dada língua.

No que tange especificamente ao uso do livro didático em contexto de ensino de língua alemã em cursos de formação de professores em nível superior, estudos como os de Bohunovsky e Bolognini (2005), Schmidt (2016), bem como de Marques-Schäfer, 
GONDAR, A; FERREIRA, M. - Desafios do uso do livro didático no ensino superior

Bolacio e Stanke (2016) vêm tematizando e discutindo a questão da centralidade destes materiais nas aulas de alemão. Uphoff (2009: 62) afirma que "[...] em conversas com colegas em congressos e outros eventos da área, é relativamente raro encontrar uma instituição de ensino de alemão no Brasil que não organiza sua grade curricular dessa forma”. Esta afirmação de Uphoff é confirmada na tese de Schmidt (2016), que conseguiu traduzir o que parecia uma hipótese em números mais precisos: das dezesseis instituições de nível superior com cursos de formação de professores de língua alemã (isto é, com a habilitação Licenciatura), quinze confirmaram o uso de livros didáticos em suas turmas. Dentre as quinze instituições que afirmaram adotar livros didáticos, o livro DaF Kompakt (objeto central desta pesquisa) figura, ao lado do livro Studio $D$, como um dos mais utilizados nas universidades brasileiras. Tal fato ressalta a importância de estudos que avancem nas reflexões e discussões sobre a forma como a adoção e o uso desses livros repercute não só direta como indiretamente sobre diferentes aspectos desse contexto. No caso específico desta pesquisa, o material em questão - o DaF Kompakt conta com um pacote didático que dispõe de, além do livro-texto (Kursbuch), objeto da presente análise, materiais de áudio em $\mathrm{CD}$, exercícios e facilidades de forma virtual, um livro extra de exercícios e o livro do professor (MARQUES-SCHÄFER; Bolacio; STANKe 2016: 573). Segundo os autores, duas razões corroboram para a preferência pelo DaF Kompakt em específico para o uso no âmbito do ensino superior de alemão: a progressão acentuada, que permite que os alunos alcancem o nível B2 ao término do sexto semestre, e o caráter culturalmente variado do livro, que contempla temáticas do universo do DACH (MARQUES-SCHÄFER; BOLACIO; STANKE 2016: 573).

\subsection{Crenças sobre ensino e aprendizagem e percepção dos}

\section{aprendizes}

Os livros didáticos, dentre outros elementos no contexto da sala de aula, podem, em muito, contribuir com a visão que o aluno tem de sua própria aprendizagem. Pode-se dizer, no entanto, mais amplamente, que o ponto-chave que motiva diferentes estudos e pesquisas sobre as crenças de professores e alunos acerca dos processos de ensinar e aprender línguas é a relação entre suas percepções ou representações desses processos e as atitudes e comportamentos que desenvolvem ao ensinar ou aprender. Muitos desses estudos (HoRwitz 1987; AlMEIDA FILHO 1993; BARCElOS 2004) evidenciam a ligação

Pandaemonium, São Paulo, v. 22, n. 37, mai.-ago. 2019, p. 302-330 
GONDAR, $A_{i}$ FERREIRA, M. - Desafios do uso do livro didático no ensino superior

direta entre o que chamam de crenças, 'miniteorias de aprender' ou até cultura(s) de aprendizagem, e os resultados obtidos nesse processo, apontando a influência direta das crenças sobre esses comportamentos ou até mesmo resultados. Uma das precursoras das pesquisas sobre crenças em contexto brasileiro, Barcelos (2007 :112) enumera diferentes aspectos (citando autores e estudos que se debruçaram sobre eles) que justificam e ressaltam a importância desse tema, entre eles, as investigações sobre a relação entre comportamentos e atitudes de aprendizes de línguas e processos de ansiedade desenvolvidos por aprendizes, investigações sobre as estratégias utilizadas pelos aprendizes ou, até mesmo, estudos sobre as abordagens utilizadas por professores (entre outros temas).

Para Almeida Filho (1993) as crenças, assim como o contexto, os atores envolvidos no processo ensino-aprendizagem, o material de ensino, entre outros, formam o que o autor chama de forças operantes, representando um papel importante no processo de ensino-aprendizagem em si à medida que impactam diretamente nos aspectos mencionados. $\mathrm{O}$ autor também ressalta um importante aspecto que deve ser considerado: idealmente, a cultura de aprender do aluno deve estar em consonância com a cultura de ensinar do professor, destacando inclusive que a desarmonia entre essas culturas pode ocasionar incompreensão, resistência, desmotivação do aprendiz, entre outros. Tal fato remete-nos a alguns questionamentos, como por exemplo, sobre modos de investigar essas crenças, torná-las objeto de reflexão e debate entre aprendentes e professores como forma de esclarecimento e ajustes de expectativas. Segundo Horwitz (1987), a partir de um trabalho de conscientização desenvolvido em sala de aula, é possível que crenças positivas possam ser reforçadas e crenças negativas, desmistificadas. Nesse sentido, podem ser encontradas pesquisas sobre mudança de crenças ao longo de um determinado período, ou após diferentes vivências e/ou experiências (BARCELOS 2007).

No que diz respeito especificamente às crenças de aprendentes acerca do livro didático e seu uso em sala de aula, poucas pesquisas foram encontradas (VIEIRA 2016; PAdilha; SElVERo 2013; Mesquita; Sousa 2015), sendo que algumas apresentavam como objeto de estudo crenças e materiais didáticos, não focando especificamente o livro didático. Ao entendermos crenças, assim como Barcelos (2004), como recursos de que os aprendentes lançam mão para "dar sentido e lidar com contextos específicos de aprendizagem" (ibidem: 143), é interessante observarmos o modo como estes dão sentido e lidam com os insumos e atividades presentes no livro com o qual estudam. Mesquita e 
GONDAR, A; FERREIRA, M. - Desafios do uso do livro didático no ensino superior

Sousa (2015), em sua investigação sobre crenças de professores e alunos do ensino fundamental ( $6^{\circ}$ ao $9^{\circ}$ anos) acerca do livro didático de inglês, apontam para alguns resultados que se mostram relevantes à presente pesquisa. Nesse estudo, grande parte dos professores defendeu o livro didático como elemento fundamental para a eficácia dos cursos. Já os alunos veem o livro como essencial para que o curso seja considerado como "bom”. Também revelam como predominante a crença na importância do foco no ensino de aspectos gramaticais, principalmente nos aprendentes. Em estudo de crenças sobre o uso de material didático e ensino de línguas estrangeiras, Padilha e Selvero (2013), ao analisarem três dissertações de mestrado sobre o tema, verificaram que seus resultados mostraram a preponderância da crença de que o material didático seria imprescindível (ibidem: 8). No entanto, é interessante ressaltar que os autores apontam uma reavaliação dessas crenças, na medida em que novas práticas metodológicas foram experimentadas pelos aprendentes.

\section{Uma abordagem exploratório-interpretativista das percepções}

\section{em torno do LD}

Ao trabalhar com um amplo espectro de turmas de ensino de língua alemã sob a perspectiva do olhar atento sobre a prática, alguns elementos do livro didático suscitaram questionamentos, tanto do ponto de vista da análise do material, quanto também de elementos determinantes para a recepção do material por parte dos alunos.

A análise do livro em si, em especial dos elementos voltados para vocabulário, gramática e tipologia de exercícios, comporá o corpo de hipóteses levantadas para avançar a investigação acerca da receptividade do material. Portanto, não apresentaremos aqui uma análise aprofundada desses aspectos do ponto de vista docente senão elementos que, a partir da observação participante, inspiraram justamente a busca pela voz dos estudantes e suas percepções acerca do processo de ensino-aprendizagem, bem como de alguns aspectos que, no andamento semanal das aulas, lhes pareceram impor desafios.

\subsection{Hipóteses norteadoras da pesquisa}

A experiência acumulada de ministração das disciplinas obrigatórias de Língua Alemã do primeiro ao oitavo período ao longo de anos de docência em nível superior levou a três 
GONDAR, A; FERREIRA, M. - Desafios do uso do livro didático no ensino superior

hipóteses. Em primeiro lugar, a atenção das pesquisadoras-docentes recaiu sobre o trabalho com vocabulário, um dos elementos centrais no ensino de $\mathrm{LE}^{7}$. Nesse sentido, pensar a gestão da aprendizagem de vocabulário faz parte da atividade do docentepesquisador e é necessário investigar criticamente as possibilidades oferecidas pelo livro didático para o curso. Assim, a literatura em didática do ensino de ALE prevê alguns elementos a serem considerados quando do trabalho com vocabulário (Wortschatzarbeit) em sala de aula, dentre eles aspectos como a escolha e organização do vocabulário, a sua acessibilidade semântica por parte do aluno e as possibilidades de exercitar e utilizar ativamente as palavras aprendidas para fins de fixação (STORCH 2009: 57). O livro DaF Kompakt destaca-se em dois aspectos frente ao Studio $D$, livro de ampla circulação no contexto de ensino de ALE no Rio de Janeiro (com primeira publicação em 2005 pela editora Cornelsen) e também utilizado em nível superior: (1) a cada lição, oferece, por um lado, uma lista de palavras de extensão considerável; (2) por outro lado, a cada lição o vocabulário parece ser essencialmente novo ainda que, ocasionalmente, o vocabulário de uma lição sirva como base para uma outra mais à frente na progressão. Uma pesquisa quantitativa seria capaz de fornecer dados mais acurados acerca do percentual de renovação vocabular entre uma lição e outra. No entanto, a lista de palavras oferecida ao final de cada lição do livro em questão pode ser considerada extensa: a primeira delas (Wörterliste), ao final da lição 1 , contém 88 verbetes ou construções ${ }^{8}$. A média de mais de cem verbetes agrupados tematicamente ao final de cada lição evidencia a intensa renovação vocabular objetivada no livro. Em nossa avaliação ao longo de ao menos quatro semestres de prática, o volume de conteúdo (Pensum) vocabular de cada lição pareceu extenso demais para o aproveitamento dos estudantes. Ao tentar desenvolver atividades que integrassem a lista de palavras às atividades pedagógicas em sala de aula, nos deparamos com o questionamento da sua eficácia como instrumento de sistematização vocabular. Nesse sentido, nos questionamos acerca de como os alunos apreendiam o vocabulário das lições em geral e, em particular, como fariam uso da lista

\footnotetext{
${ }^{7}$ Há estudos já consagrados que apontam para a reflexão sobre esse importante aspecto da aprendizagem, entre eles Bausch, K.-H., Christ, H., Königs, F., Krumm, H.-J. (orgs.). Erwerb und Vermittlung von Wortschatz im Fremdsprachenunterricht. Munique: Narr, 1995.

${ }^{8}$ A lição 5 do mesmo livro, que aborda vocabulários referentes a alimentos ("Essen und Trinken"), embalagens e pesos ("Verpackung/Gewichte"), família ("Familie") e profissões ("Berufe") conta com aproximadamente 170 entradas, desconsideradas as variações da palavra (palavras compostas, por ex., das Brot/Roggenbrot ou indicações da variante feminina: der Verkäufer/ die Verkäuferin). Se comparada à oferta de vocabulário do livro Studio $D$, cujo livro-texto não oferece lista de palavras ao final das lições, o Pensum vocabular oferecido pelo DaF Kompakt chama a atenção pela extensão.
}

Pandaemonium, São Paulo, v. 22, n. 37, mai.-ago. 2019, p. 302-330 
GONDAR, A; FERREIRA, M. - Desafios do uso do livro didático no ensino superior

de palavras: se tinham disposição em trabalhar seu conteúdo antes, em paralelo ou após as lições. Nossa primeira hipótese, que fornece subsídios para as perguntas 1 e 2 do questionário, é a de que os alunos têm dificuldades com o vocabulário das lições, que consideramos extenso, e que, em consequência disso, teriam dificuldade em usar a lista de palavras deixando-a, potencialmente, de lado.

A segunda hipótese está relacionada às atividades que envolvem a apresentação e sistematização da gramática no decorrer da lição. Com a experiência de trabalho com o livro ao longo das trinta lições que levam do nível A1 ao B1, há duas dificuldades ao ensino do conteúdo: por um lado, notamos um porcionamento evidente da apresentação de elementos gramaticais ${ }^{9}$. Por outro lado, esse porcionamento pareceu-nos pouco indutivo a partir das atividades propostas como um todo na lição. A introdução a novos tópicos gramaticais poderia ser feita com base no modelo Sammeln-OrdnenSystematisieren (FUnK; KoENIG 1991), ou seja, agregar exemplos, organizá-los em tabelas, e sistematizar o conteúdo mediante a anotação das regras referentes ao ponto gramatical. No entanto, as atividades que levam a esses novos tópicos são, por vezes, poucas e curtas. Com isso, dão a impressão de que foram dispostas com a finalidade de apresentar justamente o ponto gramatical, estando em desalinho em relação à didática de ensino da gramática em metodologias de cunho comunicativo e intercultural (ibidem). A disposição gramatical, porcionada de forma fragmentada e distribuída de forma abundante ao longo das lições, tem evidenciado ser, em nossa prática, um elemento dificultador da organização de um planejamento sequencial de atividades que contemple de forma equilibrada todas as fases da aula ${ }^{10}$. Neste sentido, o livro didático parece impor uma dificuldade a mais na construção de um sequenciamento de atividades voltado ao aprendizado por meio da comunicação. Ainda que a sistematização gramatical ao final de cada lição permita a visualização do conteúdo gramatical abordado, a apresentação gramatical durante a lição é excessiva, deslocada no contexto das lições e, por isso, de difícil inserção no andamento didático convencional. Nossa hipótese é a de que o estudante tem dificuldade com o porcionamento e posicionamento gramatical, e que esse aspecto pode ser um ponto de crítica por parte do corpo discente.

\footnotetext{
${ }^{9}$ A lição 11, já no livro A2, intitulada "Neu in Köln", em sua parte B retoma os pronomes oblíquos e apresenta os pronomes reflexivos tanto no acusativo quanto no dativo; na parte $\mathrm{C}$, composta de duas páginas, são apresentadas as declinações dos adjetivos após "ein-", "kein-" e "mein-” e, na página seguinte, as declinações dos adjetivos após "der", "die" e "das".

${ }^{10}$ Para as fases de uma aula de LE, ver Bimmel, P., Kast, B., Neuner, G. Deutschunterricht planen. FSE 18. Munique: Langenscheidt, 2003, 176p.
}

Pandaemonium, São Paulo, v. 22, n. 37, mai.-ago. 2019, p. 302-330 
GONDAR, A; FERREIRA, M. - Desafios do uso do livro didático no ensino superior

A terceira hipótese está relacionada à tipologia de exercícios oferecida no livro didático. Este conta com tipos variados de exercício, alguns com ênfase em vocabulário, outros em gramática e outros ainda, na parte oral. Acreditamos que os exercícios de vocabulário e gramaticais, a partir dos gargalos pedagógicos elencados acima (quantidade de vocábulos e apresentação da gramática ao longo da lição), sejam considerados pelos aprendentes como exercícios com caráter reprodutivo. Os exercícios comunicativos, em menor número, seriam percebidos por eles como uma exceção à regra.

A partir da discussão acerca do papel do LD no contexto de nível superior e também da relação deste com a crença dos alunos sobre sua própria aprendizagem, o questionário proposto aos estudantes buscou confrontar as hipóteses levantadas, confirmando ou refutando-as conforme a percepção do corpo discente com o objetivo de construir caminhos docentes e discentes para o melhor uso e integração do material didático ao ensino-aprendizagem de língua alemã em nível superior.

\subsection{Desenho e instrumento(s) de pesquisa}

Segundo Caspari, Helbig e Schmelter (2007), os instrumentos de pesquisa à disposição do professor-pesquisador são múltiplos. Desde mecanismos introspectivos - "técnicas de pensar alto" (Techniken des Lauten Denkens) - em que tanto discentes quanto docentes se propõem a compartilhar reflexões sobre algum aspecto do processo de ensinoaprendizagem, passando pelo registro pessoal de experiências em diários de aprendizagem ou cadernos de campo, chegando a instrumentos quantitativos e, sobretudo, qualitativos de coleta de dados (ibidem: 501). Nesse contexto, é importante que o instrumento de pesquisa seja adequado à natureza dos dados a serem coletados, que tenha fundamentação empírica (ou seja, que seja um instrumento já consagrado na pesquisa empírica por sua viabilidade e eficácia) e que aponte para a reflexividade do projeto de pesquisa em si. A pesquisa exploratória, portanto, emerge da prática e - com base em instrumentos científicos - permite voltar à prática com novo olhar. No contexto da pesquisa exploratório-interpretativa, a descrição dos informantes e condições da pesquisa é parte integrante da apresentação dos dados, haja vista corroborar a replicabilidade do experimento ou pesquisa em questão.

\subsubsection{Público-alvo e contexto de condução da pesquisa}

Pandaemonium, São Paulo, v. 22, n. 37, mai.-ago. 2019, p. 302-330 
GONDAR, A; FERREIRA, M. - Desafios do uso do livro didático no ensino superior

Os informantes da pesquisa são alunos matriculados na Habilitação Alemão cursando o segundo, o quarto e o sexto períodos da(s) disciplina(s) de Língua Alemã (cerca de trinta estudantes frequentes). A pesquisa foi feita por meio de instrumento online, com preenchimento anônimo dos questionários. Foram contatados trinta alunos por e-mail e a pesquisa permaneceu disponível online por um mês. De um total de trinta estudantes, doze responderam o questionário, configurando, portanto, menos da metade do número total.

Quanto à caracterização do meio em que a pesquisa foi aplicada, segundo Marques-Schäfer, Bolacio e Stanke (2016: 567-568, 571-572), os alunos, em sua maioria, ingressam no curso de Letras com a dupla Habilitação Português-Alemão sem conhecimentos prévios da língua alemã. A região do Rio de Janeiro, onde está situada a universidade, difere das regiões do Sul do Brasil em que a língua alemã é mais ensinada como língua estrangeira (ibidem: 571): "a população de imigrantes alemães foi muito menor no Estado do Rio de Janeiro. Por isso é compreensível que a língua alemã tenha uma importância menor no contexto escolar desse Estado"11 (MARQUES-SCHÄFER; BOLACIO; STANKE 2016: 571, tradução nossa).

A proposta da Habilitação em Alemão, que é oferecida no contexto do nível superior nos turnos da tarde e noite com um total de 25 vagas por vestibular/ano (ibidem: 572), é fornecer aos alunos a possibilidade de alcançarem o nível linguístico equivalente ao B2 ao final do oitavo semestre de aula, servindo, tanto à terminalidade do bacharelado, quanto da licenciatura (ibidem). Os autores constatam que, historicamente, os alunos não têm tido condições de financiar autonomamente um semestre de intercâmbio ou estada em algum país de expressão alemã ao longo do curso. Desta forma, tanto mais central e relevante torna-se o trabalho linguístico no contexto da sala de aula e, da mesma forma, o livro didático cumpre a função do conhecimento e aquisição de conteúdos linguísticos, extralinguísticos/ sensoriais e culturais, configurando-se em espinha dorsal das disciplinas de Língua Alemã I a VIII. Os autores mencionam também que o livro didático “DaF_Kompakt é adotado em pelo menos quatro grandes universidades brasileiras como material didático oficial no curso de formação de professores. Ainda não há pesquisas

\footnotetext{
${ }^{11}$ Do original: "[...] im Bundestaat Rio de Janeiro war die deutschsprachige Einwanderungsgruppe viel kleiner (SEYFFERTH 2000 : 11-42). Daher spielt ihre Sprache im Schulwesen verständlicherweise eine kleinere Rolle [...]".

Pandaemonium, São Paulo, v. 22, n. 37, mai.-ago. 2019, p. 302-330
} 
GONDAR, $A_{i}$ FERREIRA, M. - Desafios do uso do livro didático no ensino superior

empíricas em relação ao seu uso em contexto brasileiro"12 (MARQUES-SCHÄFER; BolaCio; STANKe 2016: 567, tradução nossa). A presente pesquisa buscou, por meio de um questionário semiaberto de nove perguntas realizado online e de forma anônima, verificar se as hipóteses levantadas seriam corroboradas pelas respostas coletadas junto aos discentes. O questionário, que teve por título "Impressões sobre o DaF Kompakt" compreendeu perguntas, divididas tematicamente entre os aspectos já referidos vocabulário, gramática e exercícios: as duas primeiras perguntas abordaram tematicamente três elementos, quais sejam, como os estudantes classificavam a quantidade de vocabulário oferecida a cada lição, a utilidade das listas de palavras ao final de cada lição e como (ou, mais precisamente, quando) o estudante teria o costume de fazer uso da lista de palavras. A pergunta 4 objetivou obter do corpo discente a informação acerca dos pontos gramaticais oferecidos na lição (se seriam poucos, em quantidade adequada ou excessivos); a pergunta 5 focou na distribuição, ao longo da lição, dos pontos gramaticais e a pergunta 6 focou na utilidade da sistematização gramatical ao final da lição; a pergunta 7 elencou tipos abstratos de exercício e solicitou que os estudantes estabelecessem um ranking de preferência e a pergunta 8 solicitava, em formato aberto, quais preferências dos estudantes estariam contempladas no livro. A pergunta 9, de caráter aberto, solicitou impressões gerais sobre livro e forneceu espaço para “comentários, críticas e sugestões". Para as perguntas semiabertas (com opções préestabelecidas de respostas e também espaço para comentários) houve a possibilidade de os estudantes acrescentarem comentários às respostas selecionadas. Assim, os comentários inseridos no tópico de apresentação e análise de dados a título de exemplificação, serão identificados com a letra "C" (referente ao termo "comentário"), seguida pelo número que se refere à ordem sequencial dos respondentes. Para as respostas de caráter mais aberto, será usada a letra "R", também seguida por um numeral. As questões propostas ipsis litteris, ou seja, em seus termos, e as respostas apuradas, bem como a discussão dos resultados, leem-se a seguir.

\footnotetext{
12 Do original: "DaF Kompakt wird seit kurzer Zeit von mindestens vier großen Universitäten in Brasilien als offizielles Material für die Lehrerausbildung verwendet. Es liegen noch keine empirischen Studien zu seiner Nutzung im brasilianischen Kontext vor".
}

Pandaemonium, São Paulo, v. 22, n. 37, mai.-ago. 2019, p. 302-330 


\subsection{Apresentação e análise das respostas ao questionário}

Quando questionados sobre a quantidade de vocabulário presente nos textos e enunciados em cada lição, vemos que a maior parte dos respondentes (7 de 12) a considerou adequada, como podemos observar na Tabela 1:

Tabela 1: Quantidade de vocabulário

1. Como você classifica a quantidade de vocabulário oferecida nos textos e enunciados das lições? (Considere apenas as 6 páginas da lição)

\begin{tabular}{c|c}
\hline $\begin{array}{c}\text { A quantidade de vocabulário novo a cada lição é pouca, compreendo os textos e } \\
\text { enunciados em grande medida a partir do conhecimento que já possuo. }\end{array}$ & 2 \\
\hline $\begin{array}{c}\text { A quantidade de vocabulário é razoável, sinto alguma dificuldade, mas nada que me } \\
\text { impeça de compreender a lição. }\end{array}$ & 7 \\
\hline $\begin{array}{c}\text { A quantidade de vocabulário é excessiva e o esforço para compreender os textos e } \\
\text { enunciados é grande. }\end{array}$ & 3 \\
\hline TOTAL & $\mathbf{1 2}$ \\
\hline
\end{tabular}

Fonte: elaboração própria

No entanto, os comentários parecem reforçar, em algumas passagens, a crítica feita por Kumaravadivelu (2001) sobre a existência de uma forte dicotomia entre aqueles que produzem os materiais, vistos como grandes especialistas, quase inequívocos; e, por outro lado, os consumidores de materiais, representando a parte que nada ou pouco sabe sobre os conteúdos ali presentes, ou mesmo sobre os seus próprios processos de aprender. $\mathrm{O}$ comentário apresentado a seguir parece corroborar essa crença de que o livro didático “sabe o que faz, por que faz e como faz", estando pouco suscetível a críticas de estudantes:

C1: "Acredito que seja proposital a média de vocabulário [...]"

Em outro comentário, mesmo considerando a quantidade de vocabulário excessiva, o respondente justifica:

C3: "Mas compreendo que isso se deve à proposta do livro em si [...]"

Pandaemonium, São Paulo, v. 22, n. 37, mai.-ago. 2019, p. 302-330 
GONDAR, A; FERREIRA, M. - Desafios do uso do livro didático no ensino superior

É interessante notar que, apesar de a maioria dos estudantes ter assinalado a opção "razoável" para a quantidade de vocabulário presente nas lições, alguns comentários parecem se aproximar da hipótese de que o volume de vocabulário poderia ser extenso demais para o aproveitamento dos alunos:

C4: "Muitas palavras da lição aparecem no vocabulário aprendido, mas só aparecem uma vez e às vezes acabam ficando meio perdidas"

C5: "O esforço [...] se dá na questão de absorver tanto vocabulário novo a cada lição, não em compreendê-lo."

Em relação à lista de palavras sistematizada ao fim de cada lição, a grande maioria dos respondentes assinalou a opção "Muito necessária/útil", como pode ser visto na Tabela 2:

Tabela 2: Lista de palavras

\section{A parte final de cada lição contém uma lista de palavras. $O$ que você acha dessa parte do livro?}

\begin{tabular}{c|c}
\hline Desnecessária/inútil & 2 \\
\hline Esporadicamente necessária/útil & 1 \\
\hline Muito necessária/útil & 9 \\
\hline TOTAL & $\mathbf{1 2}$ \\
\hline
\end{tabular}

Fonte: elaboração própria

Esses dados são extremamente relevantes, se considerarmos que o uso efetivo dessas listas envolve um trabalho mais autônomo dos aprendentes, uma vez que tais listas raramente são trabalhadas em sala de aula com o/a professor/a. Este fato é sinalizado nos comentários dos respondentes, como por exemplo:

C2: "Às vezes sinto falta de trabalhar mais com essa parte, porque ela é extremamente necessária para a compreensão da lição." 
GONDAR, A; FERREIRA, M. - Desafios do uso do livro didático no ensino superior

O trabalho de caráter mais autônomo por parte dos aprendentes também é evidenciado nos comentários:

C5: "Acho bom ter todas as palavras novas da lição reunidas em uma página. Fica mais fácil para consultar e memorizar."

C6: "Ela é, de fato, útil, por fornecer um resumo do vocabulário da lição (ajudando até mesmo na hora de revisões, pois olhando a lista de palavras podemos nos lembrar rapidamente do que a lição se tratava)"

No entanto, é interessante observar que este mesmo respondente (C6) acrescenta a seguinte informação ao seu comentário: "Não me agrada listas de vocabulário apresentadas sem contexto de uso. Não ajuda na aquisição e uso do vocabulário". Esse acréscimo em seu comentário nos remete novamente à nossa hipótese sobre a quantidade e apresentação do vocabulário presente no livro e o questionável aproveitamento efetivo deste conteúdo por parte dos aprendentes.

Do ponto de vista do ensino, a lista de, em média, trinta palavras ao final de cada lição representa um desafio ao trabalho com vocabulário (Wortschatzarbeit). A literatura especializada oferece formas diferentes de fomento à aquisição de conhecimento lexical por parte do aluno. Do ponto de vista receptivo, é possível fomentar o interesse por campos associativos já "prontos" no LD, ou mesmo oferecer inputs textuais com novos léxicos destacados ou explicados em legenda. Do ponto de vista produtivo, várias possibilidades de trabalho vocabular ativo se descortinam: a montagem de campos associativos, redes de palavras, palavras-cruzadas e a montagem de listas vocabulares próprias, com significado para o público-alvo em questão. Na prática docente, a lista de palavras impõe uma abordagem voltada ou para o trabalho discente autônomo, em casa, ou para a tentativa de contextualização dos campos semânticos à medida que a lição progride. De qualquer forma, do ponto de vista da reflexão docente, a lista de palavras do DaF Kompakt representa uma espécie de gargalo ou elemento dificultador, como referido anteriormente. Do ponto de vista da presente pesquisa, o questionário buscou apreciar o uso da lista de palavras por parte dos discentes para, a partir destes insumos, compreender se a mesma estaria sendo utilizada de forma a fomentar a aprendizagem ou se, na opinião deles, seria um elemento pedagógico 'dispensável'. Grande parte dos estudantes demonstrou em suas respostas utilizarem essas listas para estudo, principalmente como forma de memorização ou retomada do vocabulário trabalhado. A dificuldade no uso da 
GONDAR, A; FERREIRA, M. - Desafios do uso do livro didático no ensino superior

lista não se evidenciou contundentemente, o que pode significar de fato o aproveitamento do material ou mesmo a constatação de que pode ser usado como recurso pedagógico se (ou quando) necessário. Acreditamos que nessa análise caiba também acrescentarmos que, talvez a falta de uma discussão com caráter didático-metodológico em sala de aula acerca do trabalho com o vocabulário, possa ser um dos elementos a corroborar para a percepção menos crítica em relação ao material apresentado no LD. Assim, os dados referentes ao item 3 do questionário evidenciam que a lista de palavras é levada em consideração mormente ao final das lições, e, além disso, os comentários feitos pelos estudantes fornecem informações importantes acerca de aspectos como autonomia e estratégias de aprendizagem:

Tabela 3: Uso da lista de palavras

\begin{tabular}{c|c}
\hline 3. Como você faz uso da lista de palavras? Comente sua opção. \\
\hline Leio/estudo a lista de palavras antes do início da lição & 2 \\
\hline Leio/estudo a lista de palavras durante o estudo da lição & 3 \\
\hline Leio/estudo a lista de palavras após o término da lição & 7 \\
\hline TOTAL & $\mathbf{1 2}$ \\
\hline
\end{tabular}

Fonte: elaboração própria

Nesse sentido, o comentário do respondente R2 evidencia uma reflexão do estudante a respeito de seu processo de aprendizagem:

C2: "Eu fazia após, mas com o tempo vi que o trabalho durante era mais efetivo."

Deste modo, é possível detectar nos depoimentos diferentes caminhos para o estudo individual dos aprendentes, tais como atividades de tradução, sistematização de vocabulário, entre outros:

C3: "Ajuda também com as traduções das palavras."

Pandaemonium, São Paulo, v. 22, n. 37, mai.-ago. 2019, p. 302-330 
GONDAR, A; FERREIRA, M. - Desafios do uso do livro didático no ensino superior

C4: "Tento fazer um minidicionário pra não ficar perdida com as palavras novas durante a aula."

No que tange aos pontos gramaticais, quando perguntados acerca da quantidade de tópicos gramaticais ofertados pelo livro didático ao longo das lições, apenas um(a) respondente marcou a opção "excessiva”, o que aparentemente refuta nossa hipótese inicial de que a apresentação gramatical durante as lições seria demasiado excessiva.

Tabela 4: Tópicos gramaticais

\begin{tabular}{c|c}
\hline 4. Os pontos gramaticais oferecidos em cada lição... & \\
\hline ... são poucos & 4 \\
\hline ... aparecem em quantidade adequada e parecem estar em consonância \\
com o restante do conteúdo & 7 \\
\hline ...são excessivos & 1 \\
\hline TOTAL & $\mathbf{1 2}$ \\
\hline
\end{tabular}

Fonte: elaboração própria

Também chamamos a atenção no início deste artigo para possíveis dificuldades no andamento didático das aulas, devido ao fracionamento desses tópicos. Dessa forma, manifestamos nossa preocupação com uma provável dificuldade por parte dos aprendentes na compreensão e apreensão desses tópicos. Alguns comentários vão ao encontro dessa hipótese:

C11: [aparecem em quantidade adequada] "No entanto, acredito que a maneira como eles são apresentados seja muito complexa e difícil de entender aonde eles querem chegar."

C12: "O livro às vezes peca na falta de uma explicação mais extensa de certos conceitos gramaticais que não são tão simples de serem entendidos."

De todo modo, como podemos verificar na tabela 4, a maioria dos respondentes optou pela resposta em que os pontos gramaticais aparecem de forma adequada (7 em 12) e essa tendência se repete na questão seguinte: 
GONDAR, A; FERREIRA, M. - Desafios do uso do livro didático no ensino superior

Tabela 5: Distribuição dos tópicos gramaticais

\begin{tabular}{c|c}
\hline 5. Os pontos gramaticais das lições do livro aparecem... & 3 \\
\hline ... de forma bem distribuída ao longo da lição & 7 \\
\hline ... de forma razoavelmente bem distribuída ao longo da lição & 2 \\
TO. de forma insuficientemente bem distribuída ao longo da lição & 12 \\
\hline
\end{tabular}

Fonte: elaboração própria

No único comentário feito para essa pergunta, o respondente, apesar de ter assinalado a opção em que os pontos gramaticais aparecem de forma razoavelmente bem distribuída, aponta:

C8: "Eles ficam acumulados em um dos blocos do capítulo, às vezes."

Nas respostas para a pergunta 6, que versa sobre sua percepção acerca da sistematização da gramática ao final de cada lição, temos praticamente uma unanimidade: quase todos os respondentes marcaram a opção "útil" (11 de 12), sendo que apenas dois assinalaram a resposta “esporadicamente necessária/útil” e os outros nove a opção "muito necessária/útil":

Tabela 6: Sistematização gramatical

\begin{tabular}{c|c}
\hline 6. A sistematização da gramática ao final de cada lição é: \\
\hline desnecessária inútil & 1 \\
\hline esporadicamente necessária/útil & 2 \\
\hline muito necessária/útil & 9 \\
\hline TOTAL & 12 \\
\hline
\end{tabular}

Fonte: elaboração própria

A despeito de qualquer julgamento ou análise do mérito da questão (sobre a presença ou qualidade da sistematização oferecida pelo livro), pode-se depreender das 
GONDAR, A; FERREIRA, M. - Desafios do uso do livro didático no ensino superior

respostas e dos comentários dos respondentes uma sintonia com as pesquisas que apontam uma importante tendência na crença do papel de destaque que os aspectos gramaticais devem ter no livro e nas aulas de línguas. Dessa forma, a queixa que prevaleceu nos comentários dos estudantes foi a respeito de uma relativa falta de sistematização ou tabelas gramaticais em alguns capítulos do livro.

C12: "[...] algumas vezes essas tabelas são deixadas de lado pelo próprio livro."

Ou, até mesmo, a queixa incide sobre a "incompletude" das tabelas gramaticais, o que mais uma vez reforça a importância atribuída a esse aspecto:

\section{C11: "Acho bastante útil, mas geralmente superficial."}

C8: "Nem sempre é muito completa, mas mostra os pontos gramaticais que foram abordados no capítulo e ajuda a estudar."

Na questão de número 7 os aprendentes deveriam assinalar as opções que melhor corresponderiam às suas preferências sobre tipos de exercícios. Notamos, ao observar as respostas dos alunos, um relativo equilíbrio entre as respostas assinaladas como favoritas, sendo que a atividade "Exercícios em que escrevo e enceno diálogos" se destaca como a mais escolhida entre todas. Em segundo lugar aparecem, igualmente citadas, as atividades "exercícios em que posso falar alemão livremente com o colega/em classe" e "exercícios de escrita de texto".

É interessante observar que a opção menos marcada como favorita foi "exercícios online". Esse fato pode ser explicado, de um modo geral, pelo pouco trabalho com esses exercícios em sala de aula, devido, principalmente, a problemas técnicos, como o uso de equipamentos e, muitas vezes, a falta de uma boa conexão com a internet nas universidades públicas (contexto dessa pesquisa). O fato de as opções mais voltadas para o trabalho de sala de aula terem sido as escolhidas também pode espelhar o que outras pesquisas já mostraram (VAZ FERREIRA; MARQUES-SCHÄFER, 2016): a ênfase no estudo continua incidindo sobre as atividades e tarefas em sala de aula, o trabalho autônomo, realizado em casa ou em outros espaços, ficando relegado a segundo plano. 
GONDAR, A; FERREIRA, M. - Desafios do uso do livro didático no ensino superior

A questão 8, "Dos exercícios que mais gosta de fazer, quais estão contemplados no livro?", apresentou uma considerável variação de respostas. Contudo, algumas regularidades podem ser observadas nos dados. Dos doze sujeitos participantes da pesquisa, as respostas que mais se repetiram foram "todos" (presente na resposta de quatro estudantes), sem que houvesse um posicionamento sobre sua predileção, e "preenchimento de lacunas" (também citado por quatro respondentes). Numa análise geral das respostas, chama, portanto, a atenção uma aparente preferência por exercícios mais ligados à recepção (leitura e compreensão auditiva) e à reprodução com foco na forma (lacunas, múltipla escolha etc.), tendo sido citados por cinco estudantes, em detrimento dos exercícios com caráter mais aberto e produtivo, que foram priorizados por apenas três estudantes.

A análise da nona e última pergunta do questionário "Quais as suas impressões gerais sobre o livro DaF Kompakt?" nos possibilita uma retomada e discussão de algumas das hipóteses enunciadas no início deste artigo. Nesse sentido, apesar da grande variação de aspectos mencionados nas respostas, houve a preponderância das que destacaram a acentuada progressão gramatical como um elemento dificultador para o acompanhamento do curso:

R1: "O primeiro período com o DaF Kompakt foi um pesadelo. A curva era íngreme demais. Isso foi diretamente refletido na turma de 25 alunos que se transformou em 9 no período seguinte".

R2: "Acho um livro muito bom, que traz muitos conteúdos; no entanto parece 'complicar' muitas coisas, principalmente os enunciados das questões. Às vezes as tarefas são bem simples, mas os comandos são bastante dificeis de entender."

R3: "O livro que usamos é bastante rápido e fica um pouco complicado de acompanhar."

Esse aspecto corrobora nossa hipótese inicial de que a disposição muito fragmentada, e muitas vezes, excessiva da gramática poderia representar um aspecto dificultador para a compreensão dos estudantes.

Outro ponto bastante criticado está relacionado à apresentação dos tópicos gramaticais e à organização geral do livro:

R5: "Eu acho o livro muito denso. É muito conteúdo para poucas aulas. Não acho um livro prático. Acho muito confuso." 
GONDAR, A; FERREIRA, M. - Desafios do uso do livro didático no ensino superior

Tais respostas reforçam nossa impressão de que a apresentação de tópicos gramaticais está aparentemente em desalinho com as concepções didáticas que priorizam a indução a partir de aportes mais comunicativos e contextuais, isso talvez explique a afirmação do respondente:

R12: "Muito bom, porém confuso e pouco didático."

De todo modo, apesar das críticas à rápida progressão gramatical e aos temas descritos por muitos estudantes como pouco atraentes é interessante notar, em grande parte das respostas e comentários, a satisfação dos estudantes com o livro, expressa verbalmente mediante termos como "bom" ou "muito bom":

R2: "Acho um livro muito bom, que traz muitos conteúdos; no entanto parece 'complicar' muitas coisas."

R3: "É um bom livro; a parte do vocabulário e da gramática ao fim de cada lição é uma ótima ideia, ajuda bastante na hora de estudar."

Além disso, também é possível inferirmos, a partir das respostas dadas pelos estudantes, o reconhecimento de que o livro didático não é apresentado como o material perfeito (apesar de boa parte dos respondentes mostrarem-se satisfeitos com ele). Podese, desta forma, verificar como objeto de crítica a menção a aspectos pessoais de aprendizagem (nem sempre contemplados pelo livro), à adequação questionável do livro para fins acadêmicos, entre outros aspectos que foram considerados na avaliação geral do livro:

R1: "Eu acho que todos os livros têm seus prós e contras. Todos são genéricos demais (propositalmente, já que são DAF) e comerciais."

R3: "Meu método de ensino pessoal é a repetição e não vejo muito isso no livro. O livro que usamos é bastante rápido e fica um pouco complicado de acompanhar. Porém nós entendemos que é o melhor que temos, ainda mais no período que a gente se encontra." R5: "Acho que pode até ser um bom livro, para outro padrão de ensino, não para o nosso."

R6: "Em muitos aspectos ele parece ser um livro 'de cursinho', ao invés de um livro universitário." 
GONDAR, A; FERREIRA, M. - Desafios do uso do livro didático no ensino superior

Por fim, é interessante observarmos que, embora em um primeiro momento, as alternativas que atribuíam o valor de "correto" e "adequado" a aspectos específicos do livro se destacaram nas respostas ao questionário, os estudantes, quando convidados a manifestarem suas impressões gerais e críticas sobre o livro, compartilham também questionamentos apontados pelas hipóteses aqui levantadas.

\section{Conclusões finais - por uma reflexão acerca do uso de LE no ensino superior no Brasil a exemplo da pesquisa}

A presente pesquisa, de cunho exploratório-interpretativo, teve como ponto de partida as reflexões da prática docente em cursos de Letras Português-Alemão no contexto do Estado do Rio de Janeiro. A dimensão do corpo discente e do corpo docente nas universidades públicas a ofertarem o curso e, também, a ponderação acerca do material didático, feita em caráter interinstitucional com as universidades, permitem não apenas pensar com o material escolhido, mas sobretudo pensar criticamente sobre o material escolhido.

O trabalho aqui apresentado leva em consideração o que as docentespesquisadoras identificaram como gargalos no uso do LD em suas salas de aula, em nível universitário. Antes de tratar mais especificamente da captação das experiências discentes acerca dos blocos temáticos que, para as pesquisadoras, apresentavam maior desafio na prática docente (o vocabulário, gramática e a quantidade, diversidade e qualidade dos exercícios), o texto caracteriza brevemente a posição do LD no contexto do ensino de LE e também pondera teoricamente aspectos referidos às crenças e percepções discentes sobre a aprendizagem e o uso desses materiais.

Em seguida, apresenta o instrumento de pesquisa utilizado e analisa as respostas coletadas acerca das percepções de alunos sobre o livro didático em uso, com resultados que merecem ser destacados: em linhas gerais, a amostra de pesquisa apresenta uma visão mais benévola em relação ao livro didático em questão que a perspectiva das docentespesquisadoras.

Em relação ao vocabulário, no cômputo geral, os estudantes apresentam uma perspectiva includente e proativa: entendem que a lista vocabular está semanticamente contida nas lições oferecidas pelo livro e que seu melhor aproveitamento está intimamente 
GONDAR, A; FERREIRA, M. - Desafios do uso do livro didático no ensino superior

relacionado ao andamento e progressão dos conteúdos que as compõem. Nesse sentido, a dificuldade de aproveitamento da lista de palavras (Wörterliste) tal qual se apresenta no livro reside na compreensão mais acurada das pesquisadoras de que essa oferta não se encontra plenamente alinhada às expectativas de um trabalho lexical (Wortschatzarbeit) mais voltado à comunicação e de mais fácil absorção mnemônica.

Do ponto de vista do conteúdo (Pensum) gramatical, seu porcionamento ao longo das lições e seu "encadeamento lógico-progressivo", as impressões coletadas pelo questionário de certa forma fazem eco às hipóteses apresentadas no início do artigo. Para os respondentes, a oferta gramatical é "um pouco confusa", mesmo que sintam que ainda se situa no espectro do "adequado" do ponto de vista da quantidade. A percepção docente tem contornos mais críticos: identifica-se aí uma progressão particularmente íngreme, exercícios centrados no ponto gramatical, "páginas duplas" com até três pontos gramaticais novos, exigindo grande criatividade do docente na confecção de um plano de aula que proporcione aos discentes um avanço e aprendizagem incrementais. É também interessante ressaltar que essa atitude que podemos considerar como "positiva" em relação ao livro didático está de acordo com os estudos sobre crenças de aprendizagem (PADilha; Selvero 2013; Mesquita; Sousa 2015), que revelam como preponderante em aprendentes a defesa do livro didático como um instrumento essencial, fundamental ao aprendizado, em princípio, tomando como "corretas" a maioria das decisões e escolhas (relativas a aspectos como progressão, temas gerais, campos lexicais, entre outros) que apresentam.

No entanto, os resultados apontam que as reflexões suscitadas pelo questionário, que em um movimento crescente vai, ponto a ponto, convidando os estudantes a pensarem sobre diferentes aspectos do livro, culminando na questão "Quais as suas impressões gerais sobre o livro? Sinta-se à vontade para fazer comentários, críticas e sugestões", também descortinaram importantes aspectos críticos trazidos por esses mesmos estudantes. Assim, emergiram questões principalmente voltadas à importância do protagonismo dos discentes frente a seus processos individuais de aprendizagem e, no que concerne à dimensão coletiva e contextual do ambiente acadêmico em que o processo se dá, o questionamento sobre a adequação do livro didático a tal contexto. Consideramos este um dos pontos mais centrais dessa discussão, e que certamente merece figurar como foco principal de estudos futuros. A questão que se coloca é, portanto: tendo em vista o papel importante do livro didático nos processos de ensino e aprendizagem de alemão 
GONDAR, A; FERREIRA, M. - Desafios do uso do livro didático no ensino superior

como língua estrangeira e sua adoção na ampla maioria desses contextos de ensino (SCHMIDT 2016), como conciliar esta prática às finalidades próprias de cursos universitários de língua alemã, atendendo satisfatoriamente aos diferentes objetivos de estudantes nesse contexto (considerando, além disso, as especificidades das terminalidades de licenciatura e bacharelado)?

Em ampla pesquisa sobre a oferta de cursos de alemão em universidades brasileiras, Bolacio, Voerkel e Stanke (2017: 21) oferecem dados qualitativos que indicam que muitos docentes do ensino superior são a favor do uso de material didático individualmente elaborado, ainda que o uso de material didático comercial seja amplamente adotado e que não haja, ainda, dados mais específicos acerca desta produção e utilização de materiais próprios. Nesse sentido, também se configuram em importantes tópicos para estudos futuros as instituições que optaram pelo desenvolvimento de materiais autorais para o ensino da língua alemã, assim como estudos sobre a percepção dos corpos docente e discente diante das escolhas realizadas. Por fim, alguns questionamentos que podem nortear uma agenda de pesquisa construtiva sobre os cursos de alemão em contexto acadêmico brasileiro são: como adequar os materiais às necessidades dos alunos em ambas as terminalidades (bacharelado e licenciatura)? Como encontrar meios de abordar temas mais intimamente referidos à prática da "germanística", de forma geral, no contexto brasileiro? De qualquer modo, a escolha e adoção de LDs no contexto do ensino superior brasileiro precisam ser constantemente e, sobretudo, criticamente acompanhadas por especialistas da área, principalmente através de pesquisas junto aos corpos docente e discente.

\section{Referências bibliográficas}

Almeida Filho, J. C. P. Dimensões comunicativas no ensino de línguas. Campinas: Pontes, 1993.

BARCElos, A. M. F. Crenças sobre aprendizagem de línguasm Lingüística Aplicada e ensino de línguas. Linguagem \& Ensino, v. 7, n. 1, jan./jul., 2004, p. 123-156.

. Reflexões acerca da mudança de crenças sobre ensino e aprendizagem de línguas. Revista Brasileira de Lingüística Aplicada, v. 7, n. 2, 2007. p. 110-138.

BohUnovsky, R.; BologninI, C. Deutsch für Brasilianer: Begegnungen mit dem Fremden als Vorbereitung für interkulturelle Kompetenz. Zeitschrift für interkulturellen Fremdsprachenunterricht, v. 10, n. 3, 2005, p. 1-11. Disponível em: <http://tujournals.ulb.tu-darmstadt.de/index.php/zif/article/view/446/422>. Acesso em: 30.05.2018. 
GONDAR, A; FERREIRA, M. - Desafios do uso do livro didático no ensino superior

Bolacio, E.; Voerkel, P.; StAnKe, R. Material didático em cursos de alemão no contexto acadêmico brasileiro - entre conceitos gerais e específicos. In: MOURA, M. et al. (org.). Ensino-aprendizagem do alemão como língua estrangeira: teoria e práxis. Rio de Janeiro: Dialogarts, 2017, p. 15-34. Disponível em: <http://www.dialogarts.uerj.br/arquivos/E-BOOK_ENSINO-

APRENDIZAGEM\%20DO\%20ALEM\%C3\%830\%20COMO\%20L\%C3\%8DNGUA $\%$ 20ESTRANGEIRA\%20-\%20TEORIA\%20E\%20PR\%C3\%81XIS.pdf $>$.Acesso em: 03.07.2018.

CALLEGARI, M. O. V. Saborear para saber: diferentes olhares sobre a motivação em sala de aula - um estudo com alunos e professores de espanhol do Ensino Médio. Dissertação de mestrado. FE/USP, São Paulo, 2004.

CASPARI, D.; HelBig, B.; SCHMELTER, L. Forschungsmethoden: explorativ-interpretatives Forschen. In: BAUSCH, K-R.; ChRIST, H.; KRUMM, H-J. (org.) Handbuch Fremdsprachenunterricht. 5. ed. Tübingen: UTB, 2007, p. 499-506.

FunK, H.; KoenIG, M. Grammatik lehren und lernen. FS1. Munique: Langenscheidt, 1991.

HORWITZ, E. K. Surveying students' beliefs about language learning. In: WENDEN, A.; RUBIN, J. (ed.) Learner strategies in language learning. Londres: Prentice Hall, 1987, p. 110-129.

KRASHEN, S. The Input Hypothesis: issues and implications. 4. ed. Nova York: Longman, 1985.

KumaraVADIVELU, B. Toward a postmethod pedagogy. TESOL Quarterly 35, 2001, p. 537-560.

LEHNER, M. Didaktische Reduktion. Berna: UTB, 2012.

MCLAUGHLIn, B. Theories of second language learning. Londres: Arnold, 1987.

MARQUES-SCHÄFER, G.; BOLACIO, E.; STANKE, R.. Was können Lehrwerke zur Reflexion von Stereotypen im DaF-Unterricht beitragen? Eine Analyse anhand der Arbeit mit DaF Kompakt in Brasilien. Info DaF. Themenheft: Lehrwerke, 2016, p. 566-586.

MARQUeS-SChÄFER, G.; ROZENFELD, C. (org.) Ensino de Linguas e Tecnologias Móveis: políticas públicas, conceitos, pesquisas e práticas em foco. São Paulo: Edições Hipótese, 2018. Disponível em <https://nutecca.webnode.com/edicoes-hipotese-e-books/>. Acesso em: 03.07.2018.

Mesquita, I. P. A.; ARAúJo, R. N. Crenças de professores e alunos acerca do livro didático de inglês no ensino fundamental do $6^{\circ}$ ao $9^{\circ}$ anos do município de Altos - PI. Revista do Plano Nacional de Formação de Professores da Educação Básica, v. 3, n. 1, jan./jun. 2015, p. 21-25.

MourA, M. et al. (org.). Ensino-aprendizagem do alemão como língua estrangeira: teoria e práxis. Rio de Janeiro: Dialogarts, 2017. Disponível em: <http://www.dialogarts.uerj.br/arquivos/E-BOOK_ENSINO-

APRENDIZAGEM\%20DO\%20ALEM\%C3\%83O\%20COMO\%20L\%C3\%8DNGUA $\%$ 20ESTRANGEIRA\%20-\%20TEORIA\%20E\%20PR\%C3\%81XIS.pdf>. Acesso em: 03.07.2018.

Padilha, E. C.; SElvero, C. M. Crenças sobre o uso do material didático no ensino de línguas estrangeiras. Revista Linguasagem, 21. ed., 2013, p. 1-11.

PRABHU, N. S. There is no best method - Why? Tesol Quarterly, v. 24, n. 2, 1990, p. 161-176.

RÖSLER, D. Deutsch als Fremdsprache - eine Einführung. Stuttgart: Metzler, 2012.

RÖSLER, D.; SCHART, M. Die Perspektivenvielfalt der Lehrwerkanalyse - Einführung in zwei Themenhefte. Info DaF 5, 2016, p. 483-493.

SCHMIDT, C. Estudo do livro didático de língua alemã: abordagem sociocomunicativa e intercultural. Tese de doutorado em Letras, Universidade Estadual do Oeste do Paraná, 2016.

StoRCH, G. Deutsch als Fremdsprache - eine Didaktik. Paderborn: UTB, 2009.

UPHOFF, D. O poder do livro didático e a posição do professor no ensino de alemão como língua estrangeira. Tese de doutorado. IEL/Unicamp, Campinas, 2009.

Pandaemonium, São Paulo, v. 22, n. 37, mai.-ago. 2019, p. 302-330 
GONDAR, A; FERREIRA, M. - Desafios do uso do livro didático no ensino superior

VAZ FERREIRA, M.; MARQUES-SCHÄFER, G. A consultoria individual e o diário de aprendizagem como instrumentos para o desenvolvimento de autonomia no contexto de ensino de alemão como língua estrangeira. Pandaemonium Germanicum, v. 19, n. 28, 2016, p. 101123.

VIEIRA, A. N. G. Duas professoras de espanhol língua estrangeira (ELE) e suas (des)crenças sobre o livro didático. Tese de doutorado. Centro de Artes e Letras/UFSM, Santa Maria, 2016.

Recebido em 10 de julho de 2018 Aceito em 04 de novembro de 2018 